\title{
SOCIAL ENGAGEMENT AND MOTIVATION IN A MOOC ON SCHOOL LIBRARIES
}

\author{
G. Bastos, P. Cabral, V. Rocio \\ Universidade Aberta (PORTUGAL)
}

\begin{abstract}
This paper explores two editions of a MOOC delivered at Universidade Aberta's "AULAbERTA" (Open Class) platform. This platform offers different kinds of open learning paths and concerning specifically the MOOC learning path it is relevant to understand if the pedagogical model and the strategy achieve the desired results: (i) to improve education and enlarge the access to knowledge; (ii) to deliver high quality open and online education in Portuguese. The methodology used was based on a cross analysis of learner activity statistics against certain characteristics of the participants' profile like profession and motivations. Four categories of participants were identified and some aspects of their behaviours and engagement in the MOOC were examined, providing some insights concerning the level of participation and interaction. These elements can help us to understand some differences in the learning experiences connected with internal and external motivations and also how participants appreciate the online experience and course design.
\end{abstract}

Keywords: MOOC, Motivation, Social engagement, Universidade Aberta, School libraries.

\section{INTRODUCTION}

The term Massive Open Online Course (MOOC) appeared in 2008 with a course delivered by Stephen Downes and George Siemens entitled Connectivism and Connectivity Knowledge. However, it was only with the presence of the brick and mortar universities in this field that MOOC became one of the hot topics in 2012. Journals like The New York Times gave much attention to the phenomenon and a lot of opinions have been issued on this topic. On one side people were saying that $\mathrm{MOOC}$ would revolutionize Higher Education and on the other side people were stating that MOOC would die soon. None of these apocalyptic perspectives have happened. In fact MOOC have evolved in many different ways in Europe and the United States [1]. These different perspectives are based on different assumptions taken by the course developers.

In a similar way, we have seen that the research done regarding $\mathrm{MOOC}$ has taken different directions, and over the last few years many studies focused their attention, for instance, on student completion [2]. This kind of analysis are usually based on educational paradigms which are related to formal learning. However, MOOC contexts are different from formal learning. Therefore, other studies focus their attention on variables like performance [3] or engagement/motivation [4]. Among the research community, these last types of approaches seem to be more suitable to the context of MOOC, since MOOC have different purposes for their users, usually less focused on success and completion. Nonetheless, it is possible to find MOOC participants who have these aims.

Moreover, while building a MOOC, the course team might have specific purposes for having created it. In that sense, it might not be suitable to apply certain framework analysis on specific MOOC. Consequently, it should be more relevant to understand the original reasons to have created a course and then confront it with the reasons that lead learners to enrol into it. By following this approach, we are able to confirm not only if the target audience was reached, but more importantly, if their needs were being answered. Nevertheless, we should consider the possibility of having other audience that was not targeted in the first place, or even to have failed to understand the needs of our target audience.

\subsection{Types of MOOC and motivations}

As stated before, in 2008 we had the first MOOC which is known as a connectivist MOOC (cMOOC). In a nutshell, a cMOOC is an open course, where participants do not need to subscribe to it, based on network learning, where participants make connections with other people in order to build their knowledge. Moreover, each individual sets their own learning pace or rhythm and the open resources which they produced are given back to the network, so others can work upon it. Another well-known type of MOOC is the XMOOC, which stands for eXtended Massive Open Online Course, and were based 
on traditional courses often offered by face-to-face universities. These xMOOC had different levels of openness and are based on individual learning. The courses are offered in a specific platform which accommodates all the technology for assessment and content delivery. More recently, different authors [5] explore other types of principles and pedagogies in MOOC.

In 2018 Universidade Aberta (UAb) created "AULAbERTA" (Open Class) platform, with different kinds of open learning paths [6] and, concerning specifically the MOOC learning path, it is relevant to understand if the pedagogical model and the strategy are achieving the desired results: (i) to improve education and enlarge the access to knowledge; (ii) to deliver high quality open and online education in Portuguese. Regarding MOOC, UAb uses two different pedagogical approaches [7]. On one hand we can find what was called as UAbX, which is related to XMOOC approaches. On the other hand UAb developed a specific model, called iMOOC [8], which is based on the original e-learning model used for undergraduate and postgraduate courses. This specific model starts with " $\mathrm{i}$ " because it is related to the concepts of individual, interaction, interpersonal, innovation and inclusion. Participants have a learning experience based on open educational resources and they need to create open artefacts connected to the knowledge or skills defined in the course. Therefore, the interaction between the course participants is very important to the development of the created artefacts.

Regardless of the MOOC type or institutional strategy, participants have different expectations and motivations when subscribing to a MOOC. Wang [9] refers that completion rate might have a correlation with the participants' goals. However, these massive courses hold a large number of participants and, therefore, there is a complex mix of motivations present. For instance, Milligan \& Littlejohn [10] found that professionals and students who did two MOOC had different motivations: while students were more likely to cite "benefit to future career", professionals had as main motivation the relevance of the topic to the current role they have. Nevertheless, most of these motivations are based on intrinsic aspects, unless the extrinsic motivation matches their goal for doing the MOOC. Consequently, learners will continue to have different motivations and learning experiences inside each course, even though they could fit better in a XMOOC, a cMOOC, a sMOOC or any other type of MOOC.

\section{METHODOLOGY}

Taking into account the need to have research centred in the learners needs, but also the institutional aim, our main goal was to analyse if certain characteristics of the participants are related to different behaviours throughout the course. This study took place in UAb's "Open Class" platform, in a specific MOOC that had two editions in 2019. The main purpose of the open course analysed - called "The School Library and the Development of Literacies" (SLDL) [11] - was to disseminate the role and importance of the school library for the development of literacies (reading, information literacy and media literacy), and teachers were the target public.

The MOOC has a duration of 5 weeks, each week with an introductory video, readings and activities. The activities were designed in order to engage participants in discussion and sharing: for example, comments on padlet and on word clouds resulting from individual contributions to a topic; sharing of photos related to school libraries activities; presentation and discussion about different pedagogical scenarios. The course has two modalities: free course with no certificate and paid course with a certificate. The participants who want a certificate have an extra week work to produce a document with an individual reflection about the value of the MOOC concerning the initial expectations and personal motivations and goals. They have also feedback about their work.

We did a cross-analysis of the activity of the participants on the platform against their profession and motivation, in order to provide insights on the diversity of learners, their behaviours and the results of learning experiences. We first rely on Moodle analytics for the measurement, analysis and reporting of data about students and the contexts they learn through. We take into account that the aim of learning analytics in education is to understand, personalize and optimize learning and the environments in which it occurs. Then we have connected the data with a content analysis of participations in forums to examine the more concrete experience of participants in these two editions of the MOOC in order to understand their motivations and the kind of interactions that the participants build along the 5-week learning experience. 


\section{RESULTS}

This section analyses the data extracted at the end of the MOOC SLDL. These data are arranged according to participants' performance, in order to detect different profiles and motivation to participate and interact.

\subsection{Participants' profiles}

In the two editions of the MOOC we had a total of 263 participants, 114 in the first edition and 149 in the second one. From these, we only considered for this analysis active participants, i.e., all those who participated at least in one of the learning activities: 71 in $1^{\text {st }}$ edition and 60 in $2^{\text {nd }}$ edition.

The participants' initial motivations are mainly identified through a self-presentation forum where they are invited to write a post about themselves, the place they live and work, the wishes and expectations they have about the course. Based on this information, four groups of participants were identified. The target groups (teacher librarians and subject teachers) are the larger groups of participants, as expected. But we found other participants that were also engaged in the course: librarians not connected directly with the school context but that work with children and adolescents and wanted to develop their knowledge in the topic of multiple literacies and also other profiles, as a journalist, a speech therapist, students, and people interested in children's education in general. A large majority of the participants were women. The distribution of these participants can be found in table 1.

Table 1. Distribution of the active participants in the two editions (Men and Women).

\begin{tabular}{l|c|c|c}
\hline & 1st edition & 2nd edition & Total \\
\hline Teacher $(\mathrm{T})$ & $13(4 \mathrm{M} ; 9 \mathrm{~W})$ & $8(\mathrm{~W})$ & $21(4 \mathrm{M} ; 17 \mathrm{~W})$ \\
\hline Teacher Librarian $(\mathrm{TL})$ & $39(6 \mathrm{M} ; 33 \mathrm{~W})$ & $34(5 \mathrm{M} ; 29 \mathrm{~W})$ & $73(11 \mathrm{M} ; 62 \mathrm{~W})$ \\
\hline Librarian $(\mathrm{L})$ & $10(\mathrm{~W})$ & $12(\mathrm{~W})$ & $22(\mathrm{~W})$ \\
\hline Others $(\mathrm{O})$ & $9(1 \mathrm{M} ; 8 \mathrm{~W})$ & $6(2 \mathrm{M} ; 4 \mathrm{~W})$ & $15(2 \mathrm{M} ; 12 \mathrm{~W})$ \\
\hline Total & $71(11 \mathrm{M} ; 60 \mathrm{~W})$ & $60(7 \mathrm{M} ; 63 \mathrm{~W})$ & $131(18 \mathrm{M} ; 93 \mathrm{~W})$ \\
\hline
\end{tabular}

Despite being a MOOC with small numbers of enrolment, it has a variety of participant profiles, which allows an analysis oriented to the articulation between the type of participation that is performed and each profile. In the elements that are indicated as motivation for the course attendance we identify aspects such as:

- Curiosity about an area that is not dominated (T, L and O).

- Deepen the topics covered in the course (TL, T).

- Explore new ways and ideas of using SL (TL, T, O).

- Share ideas and experiences (all).

The possibility to get a certificate was also a reason to participate in the course. For Teachers and Teacher Librarians the certificate may be an extra reason for attending the MOOC because so the course can be considered as continuous training.

\subsection{Motivation and participation}

Participant characterization reveals that most participants had already some experience in the field of school libraries. This first experience in an online and open course was an opportunity to share experiences with other participants having similar responsibilities in school libraries and, as a result, in some cases the level of interaction in forums was very high.

For participants from groups TL and T the engagement with the activities in the MOOC had an external motivation, connected with the possibility to obtain a certificate. The internal motivation was related with the analysis of new contents and pedagogical scenarios that were proposed, but also with the possibility of sharing ideas and experiences with participants with distinct interests and professions.

In this sense, for a particular group (TL) the course gave an opportunity to interact with participants outside their group on the importance of the school library. In this context, a second group of participants 
which did not have experience in the field, eventually took advantage of the relative expertise of the first group.

The graphics in Figure 1 and Figure 2 are based on Moodle analytics and show engagement levels of the four groups of participants with course contents and participation in forums. The data in graphics are based on average per group during 7 weeks.
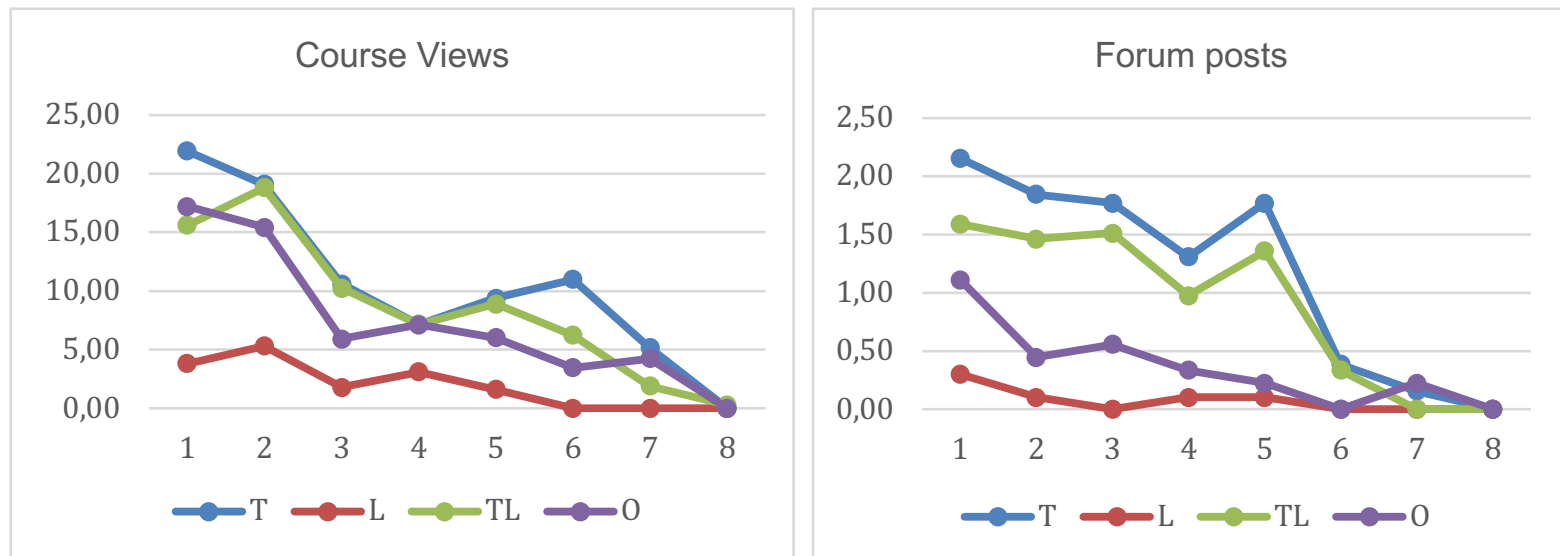

Figure 1. Graphics with $1^{\text {st }}$ edition evolution: course views and forum posts
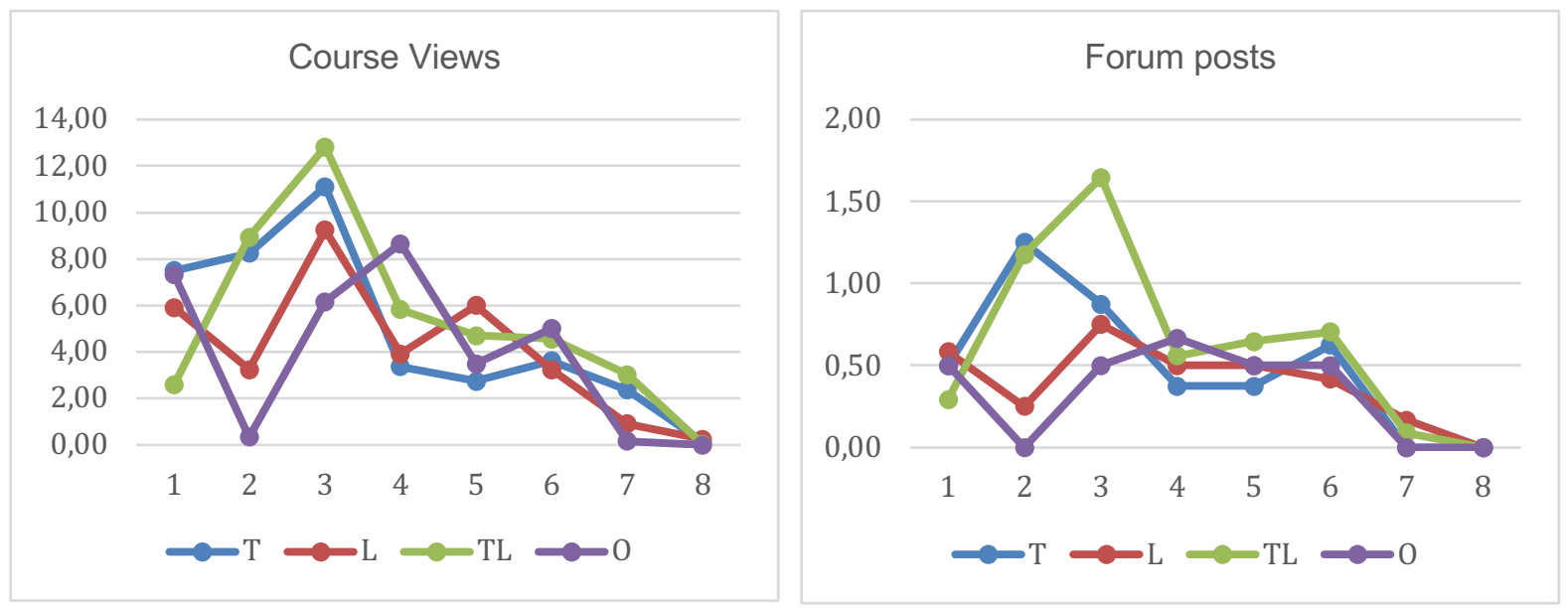

Figure 2. Graphics with 2nd edition evolution: course views and forum posts.

Comparing the two editions, there are some similarities and differences. A common feature is the declining curve in terms of course entry as it progresses, which is a common feature of research already produced on MOOC. In the 2nd edition of the course there is a greater irregularity in access to resources. In this edition the participants from group TL were more active than in the 1st edition.

We also observed that even after the course activities were completed (by the end of week 5) the different participants continued to access the course space and different resources. The exception was group $L$ in the 1 st edition and group $O$ in the 2 nd edition. In the 2 nd edition we also verified that the participants extended their interaction to the 6 th week of the course.

Forum was the main tool for discussion and for the presentation of the proposed tasks. The main objective with this option was to promote an open sharing and exchange of ideas and experiences. Activity in discussion forums is often used as a measure of MOOC users' participation [12]. In general, smaller courses have a more intense interaction in forums and this also happened in this particular MOOC. The analysis of interaction within forums can provide information on response to themes but also gives some insights, for instance, about the trajectories of participation associated with different groups.

The amount of forum posts per participant were between 1 (mainly the presentation forum) and 51 in the 1st edition and between 1 and 20 in the 2 nd edition of SLDL, with a large dispersion. The contents 
were being made available weekly so, although the number of total participations is small, many participants continue to access the course to see the new contents.

The first edition of the MOOC had a very active set of participants exchanging ideas throughout the 5 weeks of the course. Excluding the extreme value of 51 posts by only one participant, 2 participants made more than 20 posts and 11 made between 10 and 20 . Twenty eight (28) did all the activities and 25 paid for the certificate: $18 \mathrm{TL}, 5 \mathrm{~T}, 1 \mathrm{~L}$ and $2 \mathrm{O}$. In the 2 nd edition only 6 participants made between 10 and 20 posts. Twenty participants completed all compulsory activities and 18 paid to get certified: 12 $\mathrm{TL}, 5 \mathrm{~T}$ and $1 \mathrm{O}$.

As we pointed out, TL already have some expertise and reveal a predisposition to share their knowledge with other participants. This group had a positive attitude towards participants who do not master the subject with a spirit of mutual help and sharing in the sense of a greater involvement of those participants in possible future actions regarding the role of the school library. TL tried to make them value the role that SL plays in the educational process, from their point of view.

The two activities with the most participation had quite different characteristics and it can be considered that they will have motivated more interactions for two different reasons. One of the activities was carried out in 2 phases: first on a tool outside the platform (padlet) and then a forum commentary on the word clouds resulting from phase one. This type of work seemed to motivate participants, although it also benefited from an early phase of MOOC development. The other activity aroused interest especially for the theme: media literacy. This is an area that is beginning to be worked in schools and so it has also aroused a greater interest. In this last case, for example the topic on fake news proposed by one participant had several comments.

\section{CONCLUSIONS}

The results obtained are in line with other studies that focus on learner behaviour $[9,13]$. After a more enthusiastic start follows a declining curve in access and participation in the course. Several participants explicitly point out the reasons for this, which boil down to one: the lack of time to carry out the activities. We need to take into account that the MOOC participants are mainly teachers whose busy schedule makes regular study difficult but they are keen to make bursts of progress when possible.

It should also be noted that the access to a certificate had a cost. So, it might be argued that payment demonstrates commitment and those who have made that commitment are more likely to persevere.

Our results also indicate that many participants who may be classed as dropouts (for example, because they do not complete the necessary components to gain a certificate) are still participating in the course in their own preferred way (either at a slower pace or with selective engagement, participating only in just some activities).

Jordan [14] provides a compilation of available data on MOOC completion. This is an on-going initiative which provides a useful resource for basic comparisons. Completion rates may be viewed according to factors such as platform, institution and length. The graphical representation of this data illustrates a number of relationships: shorter courses have higher completion rates; small courses (with up to 200 enrolments) are much more likely to have a completion rate of over $20 \%$ than larger courses. In the case of the MOOC analysed here, 1st edition had 39,4\% completion rate and the 2nd edition 33,3\%, confirming the more general picture.

Finally, as providers we intended to offer a MOOC based on a pedagogical model where interaction among participants is important. This implies a specific design to improve collaboration and a schedule to accomplish activities. But this more structured format may pose challenges and difficulties for participants who, although interested in the course, are not available to follow the pre-set calendar.

These issues of greater or lesser flexibility in learning, although not new to distance education, continue to deserve attention. There will always be losses and gains, at the pedagogical level, with the decisions that are made. Being aware of these facts, it is up to developers to weigh what is most important and strike a balance between privileging dialogue and interaction and giving participants more control in reaching their learning objectives.

\section{REFERENCES}

[1] EADTU, Institutional MOOC strategies in Europe. Status report based on a mapping survey conducted in October-December 2014. Heerlen: EADTU, 2015. 
[2] C. Alario-Hoyos, M. Pérez-Sanagustín, C. Delgado-Kloos, H. Parada and M. C. Munoz-Organero, "Delving into Participants' Profiles and Use of Social Tools in MOOCs", IEEE Transactions on Learning Technologies, vol. 7, no. 3, 260-266, 2014.

[3] G. Fischer, "Understanding, fostering, and supporting cultures of participation", Magazine Interactions, vol. 18, no. 3, 42-53, 2011.

[4] M. Khalil and M. Ebner, "Clustering patterns of engagement in Massive Open Online Courses (MOOCs): the use of learning analytics to reveal student categories", J Comput High Educ, vol. 29, 114-132, 2017.

[5] S. Osuna-Acedo, C. Marta-Lazo and D. Frau-Meigs, "From sMOOC to tMOOC, learning towards professional transference: ECO European Project", Comunicar: Revista Científica de Educomunicación, vol. 55, no. 25, 105-114, 2018.

[6] AULA ABERTA - Aprenda gratuitamente online com a Universidade Aberta (Open Class - Learn for free online with Portuguese Open University). Retrieved from https://aulaberta.uab.pt/mod/page/view.php?id=2

[7] MOOCs at UAb. Internal Working Paper.

[8] J. Coelho, A. Teixeira, P. Nicolau, S. Caeiro and V. Rocio, "iMOOC on climate change: Evaluation of a massive open online learning pilot experience", The International Review of Research in Open and Distributed Learning, vol.16, no. 6, 152-173, 2015. https://doi.org/10.19173/irrodl.v16i6.2160

[9] Y. Wang, "MOOC learner motivation and learning pattern discovery". The 7th international conference on education data mining (EDM2014), 452-454, 2014.

[10] C. Milligan and A. Littlejohn, "Why Study on a MOOC? The Motives of Students and Professional", International Review of Research in Open and Distributed Learning, vol. 18, no. 2, 92-102, 2017.

[11] "A Biblioteca Escolar e o Desenvolvimento das Literacias": Retrieved from https://aulaberta.uab.pt/blocks/catalog/detail.php?id=8

[12] P. Hill, MOOC discussion forum: barrier to engagement?, 2013. Retrieved from http://eliterate.us/mooc-discussion-forums-barriers-engagement/

[13] D. I. F. Onah, J. Sinclair and R. Boyatt, "Dropout rates of massive open online courses : behavioural patterns". In: 6th International Conference on Education and New Learning Technologies, Barcelona, Spain, 7-9 Jul 2014. Published in: EDULEARN14 Proceedings, pp. 5825-5834, 2014.

[14] K. Jordan, MOOC Completion Rates: The Data, 2013. Retrieved from http://www.katyjordan.com/MOOCproject.html [Accessed: 23/09/19]. 